\title{
ASO Visual Abstract: Institutions Treating Breast Cancer Patients of a Low Socioeconomic Status Achieve Multidisciplinary Quality Standards at Lower Rates
}

\author{
Austin D. Williams, MD, MSEd, Robin Ciocca, DO, Jennifer L. Sabol, MD, and Ned Z. Carp, MD \\ Department of Surgery, Lankenau Medical Center, Wynnewood, PA
}

Quality breast cancer care is outlined by National Accreditation Program of Breast Centers standards. In this analysis (https://doi.org/10.1245/s10434-021-10451-x), institutions treating higher proportions of low socioeconomic status patients meet these standards for surgery and adjuvant therapy at lower rates than other institutions.

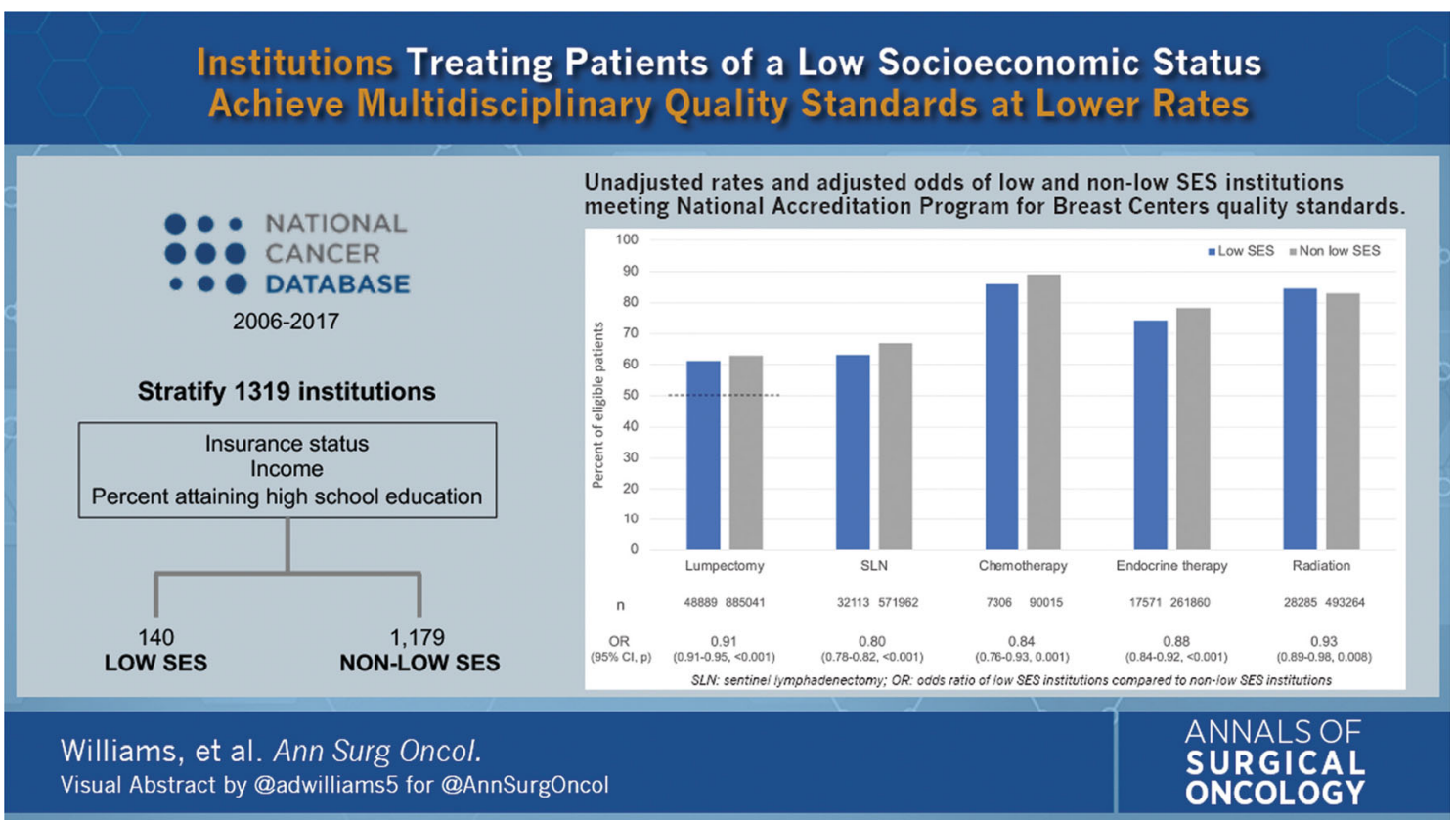

(C) Society of Surgical Oncology 2021

Published Online: 11 August 2021

A. D. Williams, MD, MSEd

e-mail: adwilliams5@gmail.com

Publisher's Note Springer Nature remains neutral with regard to jurisdictional claims in published maps and institutional affiliations. 